\title{
Phenotypic and Functional Characterization of Human Lymphocytes Activated by Interleukin-2 to Directly Inhibit Growth of Cryptococcus neoformans In Vitro
}

Stuart M. Levitz and Michele P. Dupont

The Evans Memorial Department of Clinical Research and the Department of Medicine, The University Hospital, Boston University Medical Center, Boston, Massachusetts 02118 cells (e.g., via the release of lymphokines) for antifungal activity.

In murine models, both CD4+ and CD8 + T lymphocytes are necessary for optimal host defenses against cryptococcosis (3-5), although it remains to be determined whether murine $\mathrm{T}$ cells have direct effector capacity against $C$. neoformans. In vitro, murine natural killer (NK) ${ }^{1}$ cells bind to, inhibit, and kill $C$. neoformans $(6,7)$. In vivo, the data are conflicting as to whether NK cells contribute to defenses against murine cryptococcosis. Although depletion of NK cells did not alter overall survival of mice challenged with $C$. neoformans (8), adoptive transfer of NK cells to cyclophosphamide-treated mice resulted in enhanced clearance of cryptococci from tissues (9). Interferon gamma, a product of activated $T$ and NK cells, activates murine macrophages to inhibit and kill C. neoformans (1012). However, the capacity of human interferon gamma to activate the anticryptococcal armamentarium of human macrophages could not be demonstrated (13).

Populations of human PBL, under defined conditions, have been evaluated for anticryptococcal effector cell function. C. neoformans was killed by PBMC depleted of phagocytes by carbonyl iron treatment or adherence to plastic, but only if anticryptococcal antibody ( $\mathrm{Ab}$ ) was present (14). Ab-dependent antifungal activity was lost if the cells were passed over a nylon wool column (15). Ab-dependent inhibition of $C$. neoformans was also demonstrated using a population of PBMC enriched for NK cells (16). However, in the absence of Ab, this NK-enriched population was incapable of inhibiting growth of C. neoformans even if the cells were incubated overnight with $50 \mathrm{U} / \mathrm{ml}$ of IL-2 and $50 \mathrm{U} / \mathrm{ml}$ interferon alpha (16). PBMC, cultured with cryptococcal antigens under conditions where a lymphoproliferative response occurs, can kill $C$. neoformans even in the absence of specific Ab provided that both adherent and nonadherent cells are present (17). Recently, our laboratory demonstrated that PBMC cultured with IL-2 acquire the ability to profoundly inhibit the growth of a subsequent challenge of $C$. neoformans (18). Optimal conditions for growth inhibition included a minimum of $5 \mathrm{~d}$ of incubation of PBMC with IL- 2 , a concentration of $\geq 100 \mathrm{U} \mathrm{IL}-2 / \mathrm{ml}$, and a high ratio of effectors to fungi. Moreover, the antifungal activity was shown to reside in the fraction of PBMC nonadherent to plastic. In the present study, we characterized the IL-2-induced antifungal effector cells. We found that IL-2-activated T and NK cells directly attack and inhibit the growth of $C$. neoformans.

\section{Methods}

Materials. All reagents were obtained from Sigma Chemical Co. (St. Louis, MO), except where otherwise noted. Cell culture medium was

1. Abbreviations used in this paper: $\mathrm{Ab}$, antibody; LAK, lymphokineactivated killer; NK, natural killer; SE, sheep erythrocyte. 
RPMI 1640 (Gibco Laboratories, Grand Island, NY) supplemented with L-glutamine, penicillin, streptomycin, and $10 \%$ human $\mathrm{AB}$ male serum. Flat-bottomed 96-well "half-area" polystyrene tissue culture plates (3696; Costar Corp., Cambridge, MA) were used for assays involving cell wells. Pooled human serum was obtained by combining serum from $\geq 10$ healthy volunteers under conditions preserving complement activity. Recombinant human IL-2 was a gift of Cetus Corp. (Emeryville, CA).

Incubations. Unless noted otherwise, all incubations were performed at $37^{\circ} \mathrm{C}$ in humidified air supplemented with $5 \% \mathrm{CO}_{2}$.

C. neoformans. Encapsulated, serotype D strain B3501 (also known as strain MP415) of $C$. neoformans was harvested from 4-d-old cultures grown on asparagine minimal agar medium at $30^{\circ} \mathrm{C}$, as in previous studies $(10,13,17-19)$. Under these conditions, $>90 \%$ of the $C$. neoformans were present as single cells, clumping of organisms was not observed, viability of fungi averaged $>98 \%$, and the average capsule thickness was $1.5 \mu \mathrm{M}(13,17)$.

Isolation of PBMC. Human peripheral blood was obtained by venipuncture from normal volunteers. For each set of experiments, the same blood donor was not used more than once. Blood was anticoagulated with heparin and the PBMC were purified by centrifugation on a Ficoll-Hypaque density gradient. PBMC were washed twice in PBS containing $0.1 \%$ bovine serum albumin, counted, and suspended in medium at the desired concentration (18).

Nylon wool columns. PBMC were depleted of monocytes and B lymphocytes by adherence to plastic tissue culture petri dishes for $1 \mathrm{~h}$ followed by passage of the nonadherent cells over a nylon wool column as described (20).

Sheep erythrocyte (SE) rosettes. PBMC were separated into two populations on the basis of their ability to rosette with SE (Cappel Laboratories, Malvern, PA) (21). SE were treated with $0.1 \mathrm{U} / \mathrm{ml}$ neuraminidase type $X$ for $1 \mathrm{~h}$, washed, and the SE were rotated with PBMC in RPMI 1640 containing $2 \%$ FCS for $5 \mathrm{~min}$ at $37^{\circ} \mathrm{C}$ followed by 40 min at $4^{\circ} \mathrm{C}$. Cells were then centrifuged on a Ficoll-Hypaque gradient. The rosetting cells, which formed the pellet, were rid of SE by lysis with hypotonic sodium chloride. Rosettes were not seen when the interface was examined microscopically. Cells in the pellet (hereafter referred to as the rosette fraction ) and interface were then cultured with or without IL-2 as described below.

Panning. Negative selection of cells by panning out mononuclear cell subpopulations on the basis of cell surface markers was done as described (22), except for the following two modifications: the petri dishes were coated with affinity-purified goat anti-mouse IgG (whole molecule) (Cappel Laboratories) overnight (rather than $40 \mathrm{~min}$ ) and the petri dishes were centrifuged at $160 \mathrm{~g}$ for $2 \mathrm{~min}$ at the start of the incubation with the Ab-coated cells. Preliminary studies established that both of these modifications greatly increased the efficiency of the panning. For some of the experiments, the control cells underwent the entire panning procedure except the cells were not incubated with primary Ab. These "sham-panned" cells had similar phenotypic (as determined by flow cytometry) and functional (as determined by antifungal and antitumor activities) profiles compared with control cells not sham panned.

Positive selection of lymphocyte subpopulations by panning was performed as described above for the negative selection by panning experiments, except the cells that remained adherent after five washes were directly cultured in the petri dish with medium containing IL-2. After $5 \mathrm{~d}$, the cells (which at this point were nonadherent) were collected, washed to remove free antibody, and recultured an additional 2-3 d with IL-2.

Cell culture. In $75-\mathrm{cm}^{2}$ tissue culture flasks (or petri dishes for the positive-selection experiments), effector cells $\left(10^{6} / \mathrm{ml}\right)$ were cultured for 7 or $8 \mathrm{~d}$ in medium. During this incubation period, cells were either stimulated with $1,000 \mathrm{U} / \mathrm{ml}$ of IL-2 or left unstimulated. Cells were then harvested, washed, counted, and resuspended at $10^{7} / \mathrm{ml}$ in fresh medium.

Antifungal activity of cultured PBMC. Antifungal activity was determined as described previously $(13,17,18)$. Cell wells contained $10^{6}$ (except where otherwise indicated) effector cells and $5 \times 10^{3} \mathrm{CFUs} C$. neoformans in a final volume of $150 \mu \mathrm{l}$ medium supplemented with $10 \%$ (final concentration) pooled human serum. IL-2 $(1,000 \mathrm{U} / \mathrm{ml}$ ) was added to those wells containing cells that had been previously cultured with IL-2. Wells were incubated $24 \mathrm{~h}$ at which time the number of CFUs of $C$. neoformans per well was determined by lysing the effector cells with $0.1 \%$ Triton X-100 followed by dilutions and spread plates on Sabouraud dextrose agar. Preliminary experiments established that this concentration of detergent completely lysed effector cells without affecting fungal viability.

For each experiment, two sets of cell wells were included containing C. neoformans, medium and pooled human serum, but without effector cells. The first set was detergent treated, diluted, and plated immediately. The CFUs counted were used to calculate the inoculum of live organisms added per well. The second set was incubated at $37^{\circ} \mathrm{C}$ for 24 $\mathrm{h}$ before being processed and plated. The CFUs counted were used to calculate fungal replication in medium not containing effector cells.

Results are expressed as percent growth according to the formula [(CFU experimental/CFU inoculum $)-1] \times 100$. Thus, a value of zero indicates that the number of CFUs at the start and conclusion of the incubation were the same and complete fungistasis was obtained. Values of 100,200 , and $400 \%$ indicate that the fungi underwent an average of one, two, and three replications, respectively $(13,17,18)$.

Assay for NK and lymphokine-activated killer ( LAK) cell activity. A standard ${ }^{51} \mathrm{Cr}$-release assay was performed essentially as previously described (23) using K562 erythroleukemia cells (a gift of Richard Maziarz, Portland, OR) as target cells. Effectors were incubated for $4 \mathrm{~h}$ with $5 \times 10^{3}$ targets labeled with sodium [ ${ }^{51} \mathrm{Cr}$ ] chromate (New England Nuclear, Boston, MA) at varying E/T ratios in V-bottomed wells (3894; Costar Corp.). Percent ${ }^{51} \mathrm{Cr}$ release was calculated using the standard formula [(experimental cpm - spontaneous cpm)/(total $\mathrm{cpm}-$ spontaneous $\mathrm{cpm})] \times 100$. Spontaneous $\mathrm{cpm}$ averaged $<15 \%$ of the total cpm.

Detection of cell surface antigens. Flow cytometric analysis of antigen expression on effector cells was performed for every experiment. Effector cells were incubated with antigen-specific mAb, followed by fluorescein- or phycoerythrin-conjugated goat anti-mouse IgG (whole molecule). The percentage of cells staining with each $\mathrm{Ab}$ was determined with a flow cytometer (FACScan ${ }^{\otimes}$; Becton Dickinson \& Co., Mountain View, CA) (17). Dead cells were gated out on the basis of positive staining with propidium iodide. For each sample, 10,000 events were recorded.

mAbs used to detect the indicated cell surface antigens were as follows: T3 (CD3, T cells); T4 (CD4, T cell subset), T1 (CD5, T cells, and B cell subset); T8 (CD8, T cell subset, and LAK subset); MY4 (CD14, monocytes and macrophages); anti-leu-11b (CD16, NK cells, and LAK cells); B1 (CD20, B cells), NKH-1 (CD56, NK cells, and LAK cells). All mAbs were obtained from Coulter Immunology (Hialeah, FL) except for anti-leu-11b, which was obtained from Becton Dickinson \& Co. Included in each flow cytometry run were controls using a secondary $\mathrm{Ab}$ but either no mAb or an isotypic control $\mathrm{Ab}$.

Videomicroscopy. Effector cells $\left(5 \times 10^{4}\right)$ and $C$. neoformans $(2$ $\times 10^{4}$ ) were allowed to settle to the bottom of eight-chamber Lab-Tek slides (Miles Scientific, Naperville, IL) containing a final volume of $200 \mu \mathrm{l}$ medium supplemented with $10 \%$ pooled human serum and 10 $\mathrm{mM}$ Hepes, $\mathrm{pH} 7.4$. Videomicroscopy was then performed in a $37^{\circ} \mathrm{C}$ humidified chamber using an inverted microscope (model IMT-2; Olympus Corp., Precision Instrument Div., Lake Success, NY) connected to a videocamera (CCTV model WV-1460, Panasonic, Secaucus, $\mathrm{NJ}$ ) equipped with an ocular zoom objective. Events were videotaped using a professional videocassette recorder (model AG-6010; Panasonic) on time lapse mode as described (24).

Immunoperoxidase staining. Effector cells $\left(2 \times 10^{5}\right)$ were incubated with $C$. neoformans $\left(2 \times 10^{5}\right)$ for $2 \mathrm{~h}$ in eight-chamber Lab-Tek slides containing a final volume of $200 \mu \mathrm{l}$ medium. Cells were then sequentially incubated with $100 \%\left(-20^{\circ} \mathrm{C}\right)$ methanol for $5 \mathrm{~min} ; 100 \%$ $\left(-20^{\circ} \mathrm{C}\right)$ acetone for three dips of $3 \mathrm{~s} \mathrm{each} ; 3 \% \mathrm{H}_{2} \mathrm{O}_{2}$ for $3 \mathrm{~min}$; primary $\mathrm{Ab}$ ( $\mathrm{T} 1, \mathrm{NKH}-1$, or an IgGl control) for $30 \mathrm{~min}$ at $4^{\circ} \mathrm{C}$; a 1:50 dilution 
of peroxidase-conjugated affinity-purified goat anti-mouse IgG $\left[F\left(a b^{\prime}\right)_{2}\right.$ fragment specific and adsorbed with human serum proteins; Jackson ImmunoResearch Laboratories, Inc., West Grove, PA] for 30 min at $4^{\circ} \mathrm{C}$; and $0.15 \mathrm{M}$ saline buffered with $0.05 \mathrm{M}$ Tris, $\mathrm{pH} 7.6$, containing $670 \mu \mathrm{g} / \mathrm{ml}$ diaminobenzidine and $0.024 \% \mathrm{H}_{2} \mathrm{O}_{2}$. Cells were washed with RPMI 1640 containing $0.1 \%$ FCS and $0.1 \%$ sodium azide in between incubation steps. Cells were scored under a light microscope for conjugate formation and peroxidase staining. To be counted as a conjugate, the cell membrane needed to be indented so as to partially surround the $C$. neoformans (e.g., see Fig. 6).

Statistics. Means and SE of sample groups were compared using the two-sample, two-tailed Student's $t$ test.

\section{Results}

Characterization of nonadherent PBMC. Although previous data from our laboratory demonstrated that the nonadherent (to plastic) fraction of PBMC could be activated by IL-2 to
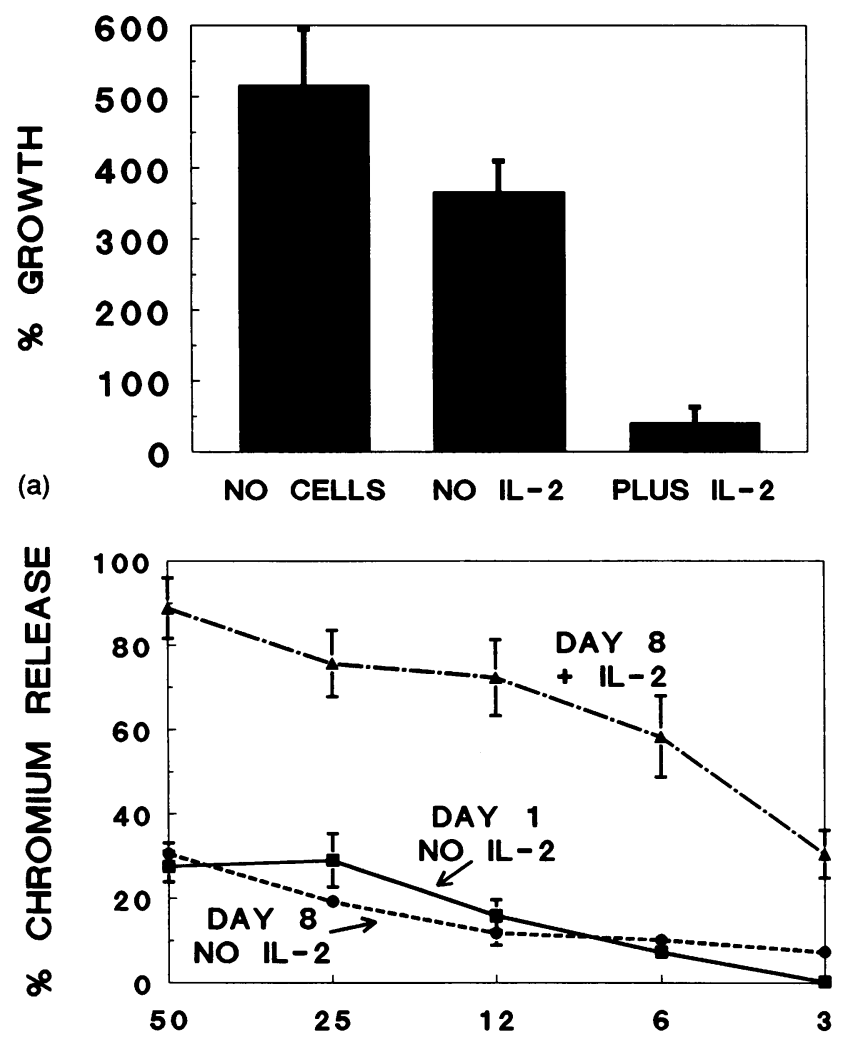

(b) EFFECTOR : TARGET

Figure 1. Fungistasis and tumor lysis mediated by IL-2-activated nonadherent PBMC. PBMC were depleted of monocytes by adherence to plastic for $1 \mathrm{~h}$ and then cultured with or without $1,000 \mathrm{U} / \mathrm{ml}$ IL-2 for $7 \mathrm{~d}$. (a) Cells were challenged for $24 \mathrm{~h}$ with $C$. neoformans in media containing $10 \%$ pooled human serum and fungal growth was assayed. (NO CELLS) Fungal growth in wells containing fungi but no effector cells. (NOIL-2 and PLUS IL-2) Fungal growth in wells containing fungi and effector cells cultured without and with IL-2, respectively. Significant fungistasis was achieved only in wells containing effector cells cultured with IL-2 $\left(P<10^{-4}\right.$ comparing the plus IL-2 group with either of the other two groups). ( $b$ ) Lysis of $\mathrm{K} 562$ cells by PBMC nonadherent to plastic cultured for $1 \mathrm{~d}$ without IL-2 (DAY 1 NO IL-2), $8 \mathrm{~d}$ without IL-2 (DAY 8 NOIL-2), or $8 \mathrm{~d}$ with IL-2 $(D A Y 8+I L-2)$. Data represent the means \pm SEM of three separate experiments performed in triplicate $(a)$ or duplicate $(b)$.
Table I. Phenotypic Changes after Culture with IL-2

\begin{tabular}{llccr}
\hline & & \multicolumn{3}{c}{ Percent expression of CD antigen } \\
\cline { 3 - 5 } \multicolumn{1}{c}{$\begin{array}{c}\text { CD } \\
\text { antigen }\end{array}$} & \multicolumn{1}{c}{$\begin{array}{c}\text { Cell } \\
\text { type }\end{array}$} & Day 2 & Day 8 & Day 8 \\
\cline { 3 - 5 } & & No IL-2 & No IL-2 & + +IL-2 \\
\hline CD3 & T Cell & $42 \pm 9$ & $77 \pm 5$ & $51 \pm 8$ \\
CD4 & T subset & $33 \pm 3$ & $60 \pm 2$ & $32 \pm 3$ \\
CD8 & T and LAK subsets & $17 \pm 1$ & $7 \pm 3$ & $35 \pm 4$ \\
CD14 & Myeloid & $34 \pm 15$ & $1 \pm 1$ & $3 \pm 1$ \\
CD20 & B cell & $11 \pm 2$ & $7 \pm 3$ & $8 \pm 3$ \\
CD56 & NK, LAK & $8 \pm 1$ & $1 \pm 1$ & $32 \pm 2$ \\
& & & &
\end{tabular}

PBMC were depleted of cells adherent to plastic, cultured for 2 or $8 \mathrm{~d}$

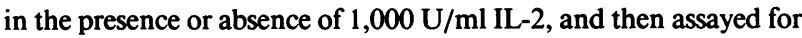
expression of cell surface markers by flow cytometry. Data are expressed as the percent of cells displaying the indicated CD antigen and represent the mean $\pm S E M$ of three separate experiments.

inhibit $C$. neoformans, the nature of the nonadherent cells was not determined. Initial experiments confirmed previous data from our laboratory demonstrating that the nonadherent (to plastic) fraction of PBMC could be activated by IL-2 to inhibit $C$. neoformans (Fig. $1 a$ ). Next, the nonadherent PBMC were characterized as to their cell surface markers and their activity against the tumor cell target K562. Consistent with data from other laboratories $(25,26)$, culture with IL-2 resulted in an increase in the percentage of cells expressing CD8 and CD56 (Table I). In the absence of IL-2, the percentage of cells expressing CD56 declined to undetectable levels. Culture with IL-2 also endowed the nonadherent PBMC with greatly enhanced capacity to lyse the tumor cell target K562 (Fig. $1 b$ ).

Effect of nylon wool columns and negative selection by panning. In the next set of experiments, PBMC were depleted of B cells and monocytes by adherence to plastic followed by passage over a nylon wool column. These procedures resulted in a population of cells that contained $<1 \% \mathrm{~B}$ cells and monocytes as determined by flow cytometry (data not shown). Cells were

Table II. Phenotypic Changes after Negative Selection by Immunological Panning

\begin{tabular}{lrlcccc}
\hline & \multirow{2}{*}{$\begin{array}{c}\text { CD } \\
\text { antigen }\end{array}$} & No IL-2 & \multicolumn{4}{c}{$+\mathrm{IL-2}$} \\
\cline { 2 - 6 } \cline { 5 - 7 } & No pan & & Sham pan & CD3/5 pan & CD16/56 pan & CD8 pan \\
\hline CD3 & $84 \pm 3$ & $76 \pm 4$ & $3 \pm 2$ & $94 \pm 3$ & $69 \pm 8$ \\
CD8 & $18 \pm 3$ & $29 \pm 5$ & $31 \pm 6$ & $28 \pm 4$ & $5 \pm 1$ \\
CD56 & $2 \pm 1$ & $17 \pm 6$ & $52 \pm 13$ & $1 \pm 1$ & $19 \pm 3$ \\
\% panned* & & $28 \pm 4^{*}$ & $83 \pm 1^{*}$ & $41 \pm 6^{*}$ & $64 \pm 5^{*}$
\end{tabular}

PBMC were depleted of cells adherent to plastic and nylon wool, cultured for $8 \mathrm{~d}$ in the absence (no IL-2) or presence (+IL-2) of 1,000

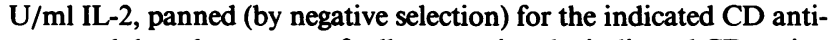
gens, and then the percent of cells expressing the indicated $C D$ antigen assayed by flow cytometry. Data are expressed as the percent of cells displaying the indicated $C D$ antigen and represent the mean \pm SEM of three separate experiments.

* Percent of cells that remained adherent to the petri dish during the panning procedure, calculated according to the formula: [1 - (cell number before panning/cell number after panning) $\times 100$. 

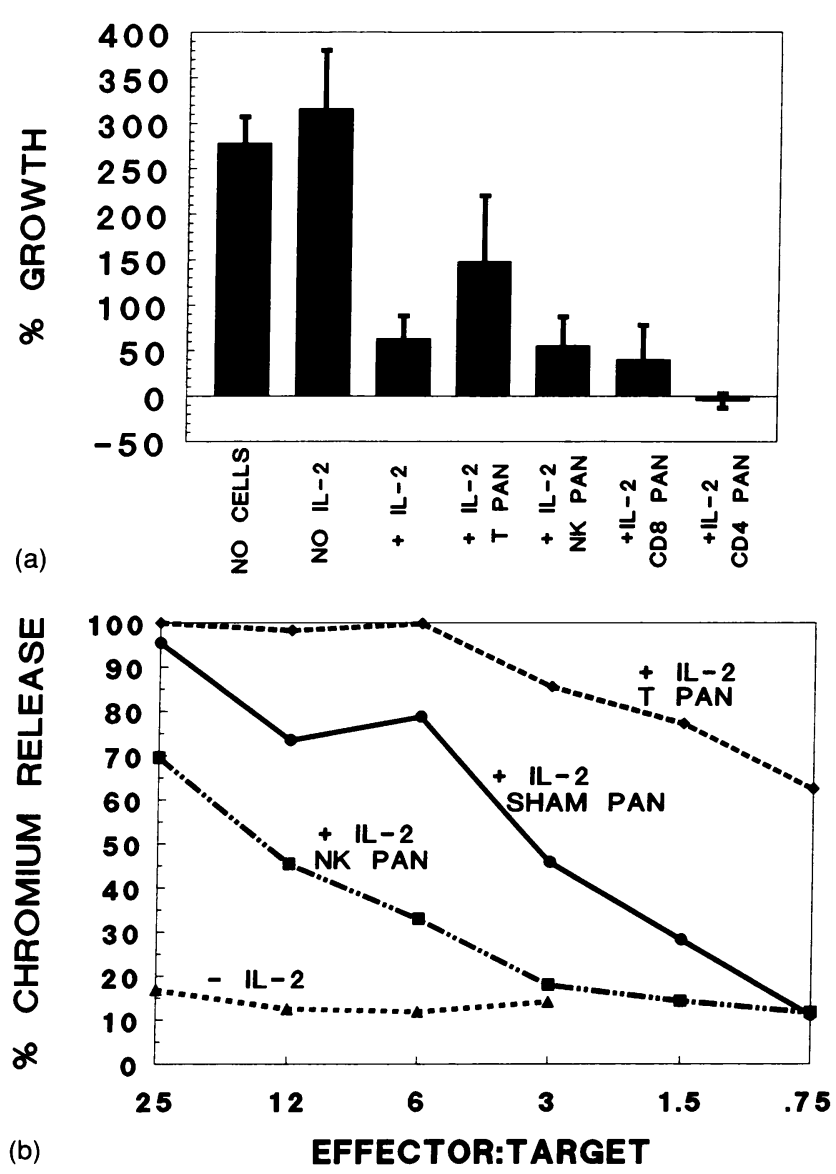

Figure 2. Fungistasis and tumor cell lysis mediated by IL-2-activated lymphocyte subpopulations. Conditions were the same as in fig. 1, except PBMC were depleted of monocytes and B cells by adherence to plastic and nylon wool and then were incubated with or without $1,000 \mathrm{U} / \mathrm{ml} \mathrm{IL}-2$ for $7 \mathrm{~d}$. Cells in the plus IL-2 group were then depleted of specific cell populations by panning, as described in Methods. (a) Cells were challenged for $24 \mathrm{~h}$ with $C$. neoformans and fungal growth assayed. Significant fungistasis was achieved only in wells containing effector cells cultured with IL-2. $\left(P<10^{-3}\right.$ comparing $N O$ $C E L L S$ or $N O I L-2$ with any other group). Panning CD3+ and CD5+ cells $(+I L-2 T P A N)$, but not CD16+ and CD56+ cells (+ IL-2 NK PAN), CD8+ cells (+IL-2 CD8 PAN), or CD4+ cells $(+I L-2 C D 4 P A N)$, resulted in a significant loss of fungistasis $(P$ $=0.008)$ compared with cells not panned $(+I L-2)$. Data represent the means \pm SEM of seven separate experiments performed in triplicate, except for the CD4 PAN group which represents two separate experiments performed in triplicate. $(b)$ Lysis of K 562 cells by effector cells cultured $7 \mathrm{~d}$ either without IL-2 $(-I L-2)$ or plus IL-2 and then panned as in $(a)$. Results shown are from a representative experiment. Two other experiments yielded similar results.

then cultured for 7 or $8 \mathrm{~d}$ with or without IL-2 and depleted of cells expressing specific surface markers by panning. Panning cells expressing CD3 and CD5 ( $\mathrm{T}$ cells) reduced the $\mathrm{T}$ cell population by $96 \%$ (from 76 to $3 \%$ ) as measured by expression of CD3 ( Table II ). This T cell-depleted population had significantly reduced antifungal activity (Fig. $2 a$ ) but greatly enhanced activity against the tumor target K562 (Fig. $2 b$ ). In contrast, when the cell population was depleted of cells expressing CD16 and CD56 (NK and LAK phenotype), antitumor activity was diminished whereas antifungal activity remained unchanged. Panning cells expressing CD8 (an antigen found on a subset of T cells and LAK cells) or CD4 (an antigen expressed on a $\mathrm{T}$ cell subset) did not significantly affect antifungal activity. Lysis of K562 targets by CD8-depleted or CD4depleted effectors was not tested.

Antifungal activity appeared to require cell contact, as supernatants obtained after culture of both fungal-stimulated and unstimulated IL-2-activated nylon wool nonadherent PBMC failed to inhibit growth of $C$. neoformans. In fact, in three separate experiments, supernatants supported significantly $(P$ $<0.002$ ) greater fungal growth (growth in wells containing fungal stimulated and unstimulated supernatants was $567 \pm 35$ and $620 \pm 48 \%$, respectively, compared with $416 \pm 25 \%$ growth in wells containing medium alone). Next, experiments were performed examining the antifungal activity of IL-2-activated, nylon wool-nonadherent PBMC at varying effector / fungus ratios. In three separate experiments, growth was $110,304,447$, 469 , and $563 \%$ at ratios of 200:1, 50:1, 12.5:1, and 3:1, and $0: 1$ (no effector cells), respectively $(P<0.02$ comparing 200:1, 50:1, or 12.5:1 with no effector cells). IL-2-activated lymphocytes mediated nearly identical levels of fungistasis regardless of whether the serum in the system was heated to $56^{\circ} \mathrm{C}$ to destroy complement activity (data not shown).

Effect of rosetting. PBMC were next separated on the basis of their ability to form rosettes with SE. Virtually all $T$ cells and a subpopulation of NK cells express CD2 and form rosettes when incubated with SE. In some experiments, NK cells were depleted from the rosetting cells by panning CD56+ and $\mathrm{CD} 16+$ cells. As expected, the rosette fraction was greatly enriched for $\mathrm{T}$ cells whereas the interface consisted mainly of NK cells, B cells, and monocytes (Table III). Cell fractions were then cultured for 1 wk with or without IL-2, at which time antifungal activity was assayed and flow cytometry was repeated. Pronounced antifungal activity was seen in the rosette fraction, but only when cultured with IL-2 (Fig. $3 a$ ). Panning CD16+ and CD56+ cells from the rosette fraction, either at the start of the incubation (Fig. $3 a$ ) or immediately before fungal challenge (data not shown) had no significant effect on antifungal activity but markedly diminished antitumor activity (Fig. $3 b$ ).

Table III. Cell Surface Antigens after Rosetting with SE

\begin{tabular}{|c|c|c|c|c|c|c|c|c|}
\hline \multirow{2}{*}{$\begin{array}{c}C D \\
\text { antigen }\end{array}$} & \multicolumn{3}{|c|}{ Rosette } & \multicolumn{2}{|c|}{$\begin{array}{c}\text { Rosette + NK } \\
\text { pan }\end{array}$} & \multicolumn{3}{|c|}{ Interface } \\
\hline & dl & d8- & d8+ & dl & d8+ & dl & d8- & d8+ \\
\hline CD3 & 77 & 85 & 77 & 85 & 95 & 9 & 1 & 0 \\
\hline CD14 & ND & 0 & 0 & ND & ND & 26 & 41 & 58 \\
\hline CD20 & 5 & 3 & 0 & 7 & ND & 45 & 33 & 9 \\
\hline CD56 & 11 & 8 & 19 & 3 & 1 & 10 & 13 & 11 \\
\hline
\end{tabular}

PBMC were separated into rosette and interface fractions based on their ability to rosette SE. Some of the rosetted cells were then depleted of NK cells by panning (by negative selection) for CD16 and CD56 (Rosette + NK pan). Cells were then cultured for 1 (d1) or 8 $\mathrm{d}$ in the absence $(\mathrm{d} 8-)$ or presence $(\mathrm{d} 8+)$ of $1,000 \mathrm{U} / \mathrm{ml} \mathrm{IL-2}$ and assayed for expression of cell surface markers by flow cytometry. Data are expressed as the percent of cells displaying the indicated CD antigen. Results for CD3 and CD56 represent the mean of three to six separate experiments. Results for CD20 and CD14 represent one experiment for the rosette groups and three experiments for the interface groups. SEM (not shown) averaged $<5 \%$. 
Surprisingly, the interface had excellent antifungal activity both in the presence and absence of IL-2 (Fig. $3 a$ ). Moreover, addition of cells from the unstimulated rosette fraction abrogated the antifungal activity of the unstimulated cells in the interface. Further attempts to define the phenotype of the antifungal effector cells in the interface, either by passage over a nylon wool column or panning, were unsuccessful due to the low cell yields obtained at the end of those procedures.

Effect of positive selection by panning. Next, nylon woolnonadherent PBMC were positively selected by panning for
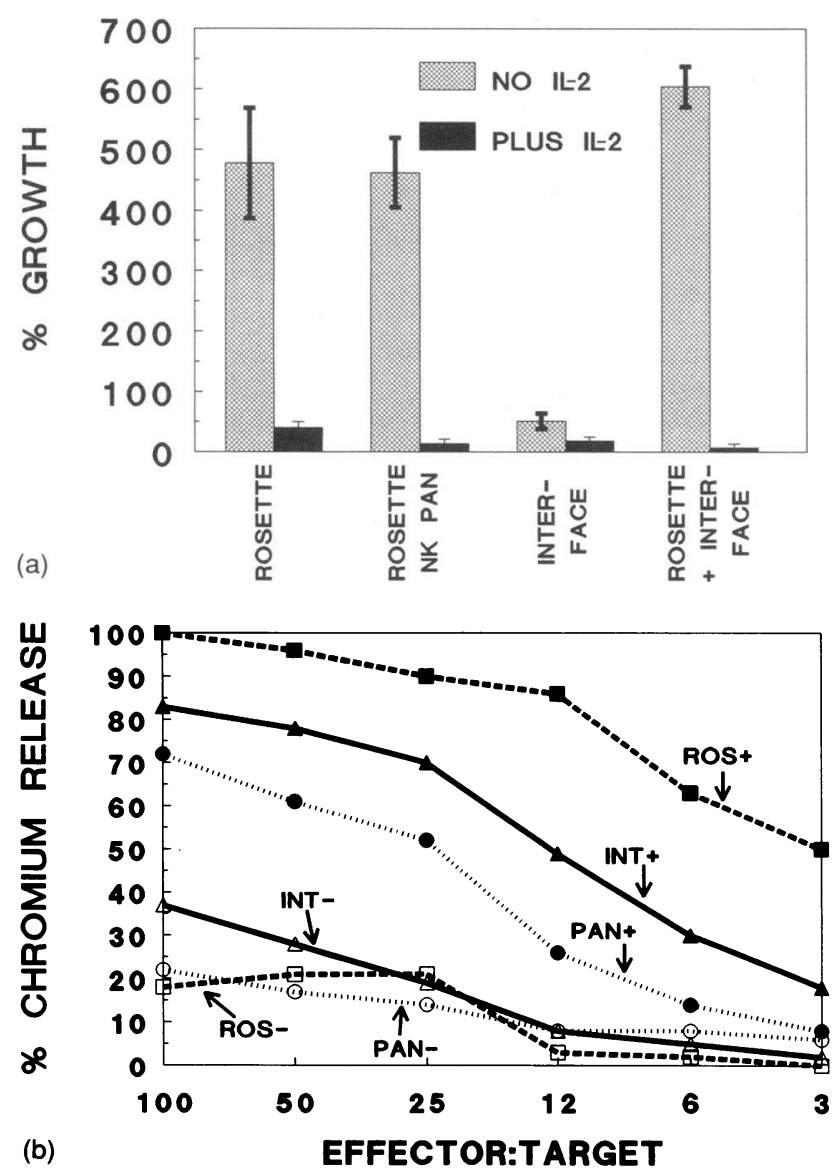

Figure 3. Fungistasis and tumor cell lysis mediated by IL-2-activated and unactivated PBMC separated on the basis of their ability to rosette SEs. The rosetting (ROSETTE) and nonrosetting (INTER$F A C E$ ) cells were cultured $7 \mathrm{~d}$ with (PLUS IL-2) or without (NO $I L$-2) $1,000 \mathrm{U} / \mathrm{ml} \mathrm{IL-2}$. Some of the rosetted cells were then depleted of CD16+ and CD56 + cells by panning (ROSETTE NK PAN). (a) Cells $\left(10^{6}\right)$ were challenged for $24 \mathrm{~h}$ with $C$. neoformans and fungal growth was assayed. Nearly complete fungistasis was obtained in all groups cultured with IL-2, and in the interface, even in the absence of IL-2. Addition of cells $\left(10^{6}\right)$ from the rosette fraction to cells $\left(10^{6}\right)$ from the interface (ROSETTE + INTER-FACE) resulted in a loss of fungistasis in the group cultured with no IL-2. Not shown on the graph, growth was $709 \pm 39 \%$ (mean \pm SEM) in wells containing $C$. neoformans but no effector cells. Data represent three to nine separate experiments performed in triplicate. (b) Lysis of K562 cells. ROS, rosetted cells; $I N T$, cells in the interface; $P A N$, cells in the rosette fraction depleted of $\mathrm{CD16+}$ and $\mathrm{CD56}+$ cells by panning. + and - refer to the presence and absence, respectively, of IL-2. Results shown are from a representative experiment. Two other experiments yielded similar results.
Table IV. Cell Surface Antigens after Positive Selection by Panning

\begin{tabular}{lccccc}
\hline & & \multicolumn{4}{c}{$+\mathrm{IL}-2$} \\
\cline { 3 - 6 } $\begin{array}{c}\text { CD } \\
\text { antigen }\end{array}$ & $\begin{array}{c}\text { No IL-2 } \\
\text { No pan }\end{array}$ & No pan & CD4 pan & CD8 pan & CD16/56 pan \\
\hline CD3 & $93 \pm 1$ & $90 \pm 1$ & $79 \pm 7$ & $68 \pm 7$ & $14 \pm 8$ \\
CD4 & $78 \pm 4$ & $61 \pm 4$ & $75 \pm 7$ & $3 \pm 1$ & ND \\
CD8 & $18 \pm 5$ & $27 \pm 3$ & $7 \pm 2$ & $79 \pm 7$ & ND \\
CD14 & 0 & 0 & 0 & 0 & 0 \\
CD56 & $1 \pm 1$ & $9 \pm 3$ & $10 \pm 6$ & $25 \pm 8$ & $73 \pm 7$
\end{tabular}

Nylon wool-nonadherent PBMC were either not panned or panned by positive selection for CD4+, CD8+, or CD16/56+ cells. Cells were then cultured for $8 \mathrm{~d}$ in the absence (No IL-2) or presence $(+\mathrm{IL}-2)$ of $1,000 \mathrm{U} / \mathrm{ml} \mathrm{IL-2}$ and the percent of cells expressing the indicated $\mathrm{CD}$ antigen determined by flow cytometry. Data are expressed as the percent of cells displaying the indicated $C D$ antigen and represent the mean $\pm S E M$ of four separate experiments.

CD4+, CD8+, or CD16/56+ cells. Cells were then cultured for 1 wk with IL-2, at which time expression of cell surface markers ( Table IV) and antifungal activity (Fig. 4) were determined. Over $70 \%$ of the cells expressed the cell surface antigen(s) that were positively selected for. Significant growth inhibition was seen with all three cell types at both effector/fungus ratios tested.

Videomicroscopy. Videomicroscopy of nylon wool-nonadherent PBMC cultured with IL-2 for $7 \mathrm{~d}$ and then challenged with $C$. neoformans demonstrated conjugate formation between effector cells and their fungal targets. Effector cells repeatedly made contact with $C$. neoformans, often spreading to completely cover the fungal target (Fig. 5). In eight separate observations, effector-target conjugate formation lasted $11.9 \pm 3.0$

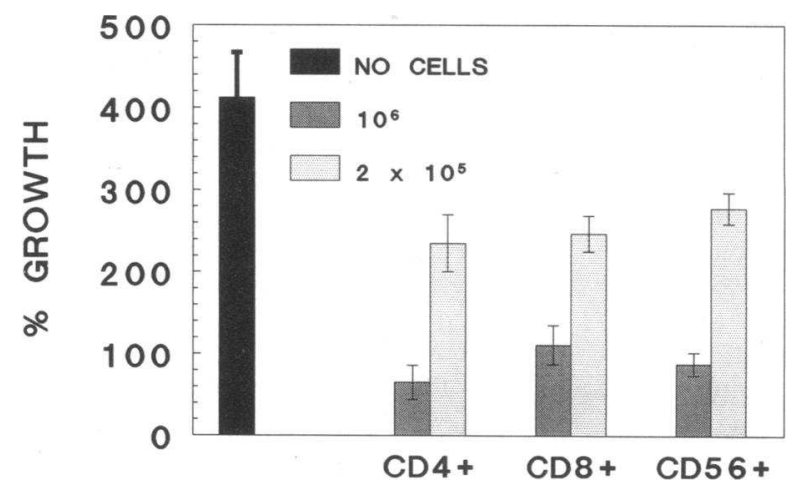

Figure 4. Fungistasis mediated by IL-2-activated lymphocytes purified by positive selection. Nylon wool-nonadherent PBMC were panned for CD4+, CD8+, or CD16/56+ cells. Positively selected cells were cultured for $7 \mathrm{~d}$ in the presence of $1,000 \mathrm{U} / \mathrm{ml} \mathrm{IL-2, \text {and }}$ then challenged for $24 \mathrm{~h}$ with $C$. neoformans and fungal growth was assayed. Two different concentrations of effector cells $\left(10^{6}\right.$ and 2 $\times 10^{5}$ ) were tested. Results are from three to four separate experiments performed in triplicate. $P \leq 0.001$ comparing the percentage growth in the absence of effector cells $(N O C E L L S)$ with percentage growth in the presence of $10^{6} \mathrm{CD} 4+, \mathrm{CD} 8+$, or CD56+ cells. $P$ $\leq 0.01$ comparing the percentage growth in the absence of effector cells with percentage growth in the presence of $2 \times 10^{5} \mathrm{CD} 4+$ or CD8+ cells. 

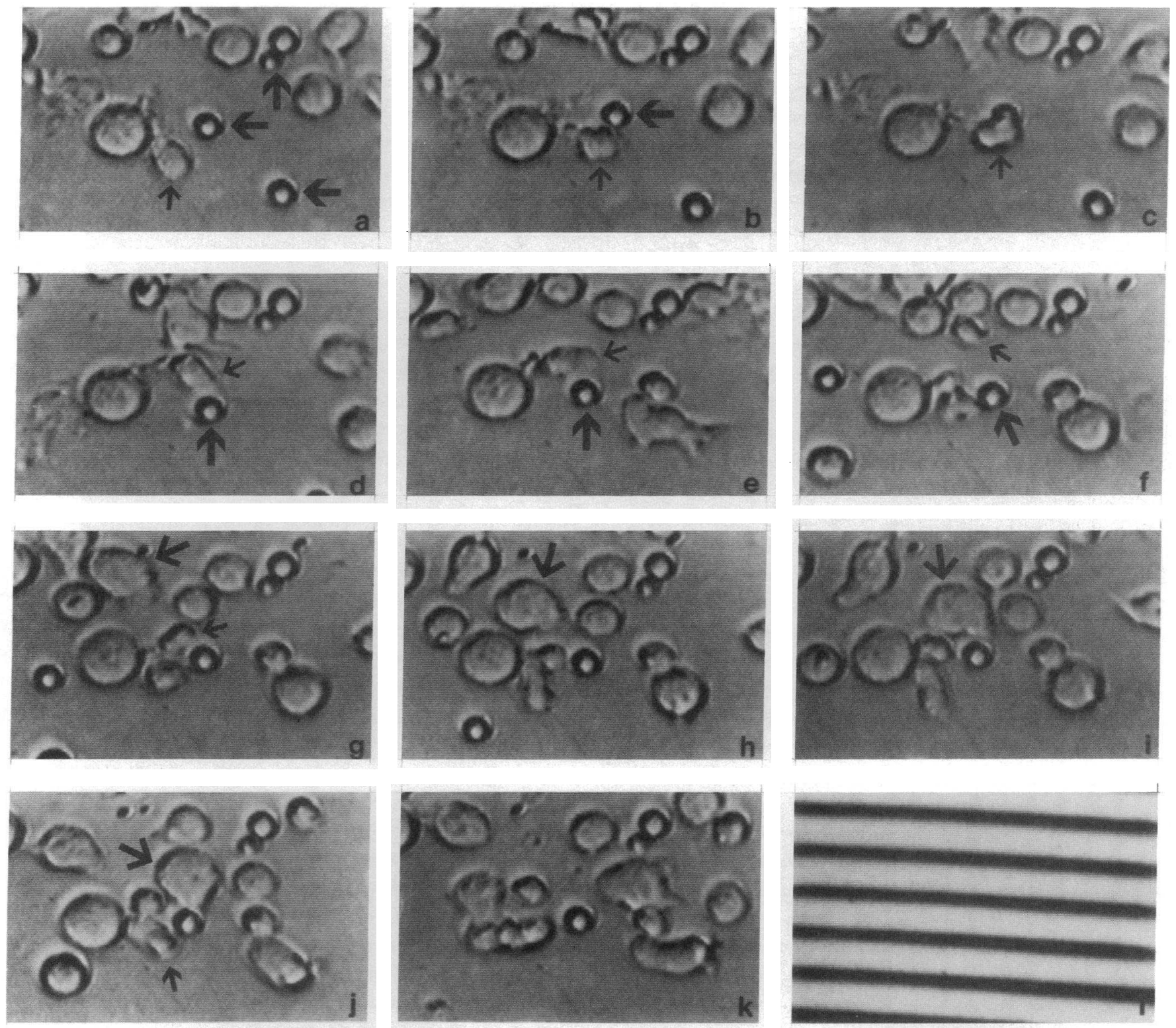

Figure 5. Videomicroscopy demonstrating conjugate formation between IL-2-activated T cells and C. neoformans. PBMC were depleted of B cells and monocytes by adherence to plastic and nylon wool, cultured for $7 \mathrm{~d}$ with $1,000 \mathrm{U} / \mathrm{ml} \mathrm{IL-2}$, and finally depleted of cells with NK phenotypes by panning out CD16+ and CD56+ cells. $a-k$ demonstrate three effector cells attacking a single yeast cell during a 1-h time course. (a) time $=0$, before contact. Large arrows point to yeast cells and small arrow to lymphocyte 1 . Note the heterogeneity in size among the lymphocyte population; $(b)$ time $=0.5 \mathrm{~min}$. Lymphocyte 1 (small arrow) has made contact with a yeast cell $($ large arrow); $(c)$ time $=1.4$ min. Lymphocyte 1 (arrow) has spread over the yeast cell; $(d$ and $e$ ) time $=3.7$ and 12.8 min, respectively. Lymphocyte 1 (small arrow) partially surrounds and continues to attack the yeast cell (large arrow) from multiple angles; $(f)$ time $=14.8$ min. Lymphocyte 1 is retreating from the yeast cell (large arrow). Lymphocyte 2 (small arrow), a small lymphocyte, is moving towards the yeast cell; $(g)$ time $=41.3 \mathrm{~min}$. Lymphocyte 1 has retreated. Lymphocyte 2 (small arrow) has made contact with the yeast cell. Lymphocyte 3 (large arrow), a large lymphocyte, is now moving towards the yeast cell; $(h)$ time $=46.1 \mathrm{~min}$. Lymphocyte 2 has begun to retreat. Lymphocyte 3 (arrow) is about to make contact; $(i)$ time $=50.0 \mathrm{~min}$. Lymphocyte $3($ arrow $)$ has made contact; $(j)$ time $=54.3 \mathrm{~min}$. Lymphocyte 3 (large arrow) continues to attack the yeast cell. Lymphocyte 1 (small arrow) has again made contact with the yeast cell; $(k)$ time $=60.0$ min. The lymphocytes have all retreated; $(l)$ stage micrometer at the same magnification used for $a-k$. Distance between lines $=10 \mu \mathrm{m}$.

$\min$ ( mean \pm SEM, range 4.0-30.6 min). Conjugates were still seen if the effectors were depleted of CD56+ and CD16+ cells by panning.

Immunoperoxidase staining. The final set of experiments sought to determine the phenotype of the cells responsible for conjugate formation. Nylon wool-nonadherent PBMC were cultured for $7 \mathrm{~d}$ with IL-2, challenged for $2 \mathrm{~h}$ with an equal number of $C$. neoformans in the presence of $10 \%$ pooled human serum, and then fixed and immunoperoxidase stained. Conjugates consisting of both CD5+ and CD56+ cells were observed (Fig. 6). Effector cells often dramatically changed their shape to partially surround the fungus. In one representa- 

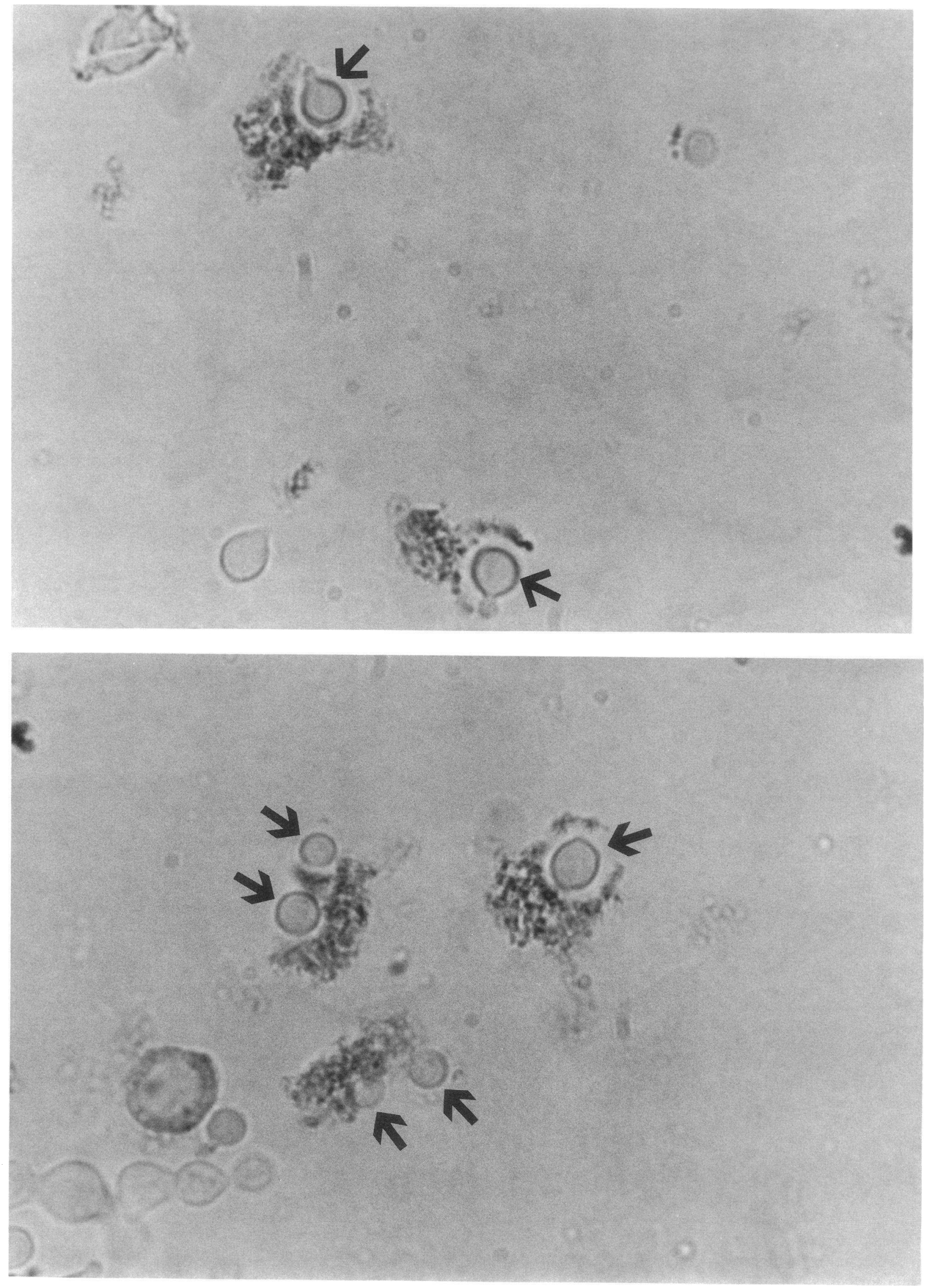

1496 S. M. Levitz and M. P. Dupont 
tive experiment, $2.0 \%$ of the effector cells were conjugated with one or more $C$. neoformans. Of the cells forming conjugates, 57,12 , and $0 \%$ stained positive for CD5, CD56, and a control $\mathrm{Ab}$, respectively.

\section{Discussion}

The data presented here establish that human lymphocytes, when activated by IL-2, are capable of attacking and inhibiting the growth of $C$. neoformans. Two distinct lymphocyte populations, $T$ cells and NK cells, mediated anticryptococcal activity.

Highly purified populations of IL-2-activated T cells obtained by three different techniques effected nearly complete fungistasis. Fungistasis was partially abrogated by depletion of $T$ cells from nylon wool-nonadherent PBMC. Highly purified IL-2-activated $T$ lymphocytes made contact with and spread over $C$. neoformans, as demonstrated by videomicroscopy. Finally, the majority of nylon wool-nonadherent PBMC forming conjugates with $C$. neoformans were $\mathrm{T}$ cells as determined by immunoperoxidase staining. Both $\mathrm{CD} 4+$ and $\mathrm{CD} 8+\mathrm{T}$ cells had activity.

In general, $\mathrm{T}$ cells are thought to mediate antimicrobial activity either by releasing lymphokines that activate other cell types (e.g., macrophages) or by MHC-restricted lysis of infected cells. The data presented herein strongly suggest that IL-2-activated T cells are capable of attacking $C$. neoformans and directly mediating anticryptococcal activity without MHC restriction. Other investigators have demonstrated that splenic CD8+ T cells, obtained from mice immunized with Pseudomonas aeruginosa polysaccharide antigen, secrete a bactericidal lymphokine (27-29). The bactericidal effect occurred in the absence of $\mathrm{Ab}$ or complement and did not require phagocytic cells. Moreover, antigen-specific murine splenic CD8+ T cells were directly parasiticidal to extracellular Toxoplasma gondii (30), and MHC-unrestricted "promiscuous" killing of tumor targets by CD4- CD8 - T cells has been demonstrated (31).

In addition to $T$ cells, a second population of IL-2-treated lymphocytes was active against $C$. neoformans. Cells nearly totally depleted of $T$ cells by virtue of panning or their failure to rosette with SEs still mediated fungistasis. Moreover, NK cells obtained by positive selection were fungistatic. These data and the immunoperoxidase data showing $C$. neoformans partially surrounded by CD56+ IL-2-activated lymphocytes provide compelling evidence that this second population is comprised of cells with the NK phenotype. However, because cell separation techniques do not yield $100 \%$ pure populations, we cannot entirely exclude the possibility that at least some antifungal activity is mediated by a third population of cells expressing neither $\mathrm{T}$ cell nor NK cell markers.

Although clearly there are profound differences between NK cells and $T$ cells, there are similarities that may help explain the apparent ability of both activated NK and T cell types to effect fungistasis. For example, many mechanisms of cytoly- sis are shared between NK and T cells, and recent evidence suggests that NK and T cells may arise from a common progenitor that expresses components of the CD3 complex (32). In addition, some IL-2-activated lymphocytes express both NK and $T$ cell markers $(25,26)$.

To our knowledge, our data are the first to show human cells with a $\mathrm{T}$ phenotype can have direct antimicrobial activity. Other investigators have found human NK cells possess antibacterial activity. Abo et al. (33) found a subpopulation of large granular lymphocytes phagocytosed and killed Staphylococcus aureus, but not Gram-negative bacteria, Candida albicans, or baker's yeast. In contrast, Garcia-Penarrubia et al. (34) found NK cells killed both Gram-positive and Gram-negative bacteria and that killing was extracellular without evidence of phagocytosis. Recently, Beno and Mathews (35) demonstrated growth inhibition of $C$. albicans by IL-2-activated plastic-nonadherent human PBMC. However, the active cell fractions were not characterized.

Interestingly, the cells that did not rosette with SEs were fungistatic even if cultured without IL-2. Moreover, in the absence of IL-2, rosetting cells inhibited the antifungal activity of nonrosetting cells. Since the rosetting cells are mostly $T$ cells, one hypothesis to explain these data is that $\mathrm{T}$ cells bind $C$. neoformans but are only fungistatic when activated. In contrast, nonrosetting cells are constitutively fungistatic but, in the presence of rosetting cells, do not effectively bind their targets because of physical interference from the rosetting cells. Alternatively, the unactivated rosetting cells may be directly suppressive.

Future experiments will be needed to establish the mechanisms whereby activated lymphocytes mediate their antifungal effects and the lymphocytic receptors and fungal ligands responsible for the interaction. Complement receptors and Fc receptors do not appear critical, since specific $A b$ was not added and inhibition was seen even if the serum was heated to destroy complement activity. Moreover, T cells do not generally express Fc receptors, although a subpopulation may express complement receptors (36). The recent finding that CD3 + cells from patients receiving IL-2 immunotherapy may express receptors for $\mathrm{C}$-reactive protein raises the possibility that receptors not present on resting $T$ cells may be induced on activated $\mathrm{T}$ cells (36).

The videomicroscopy and immunoperoxidase results are consistent with those of other investigators who have demonstrated that LAK cells are highly motile and capable of forming protopods or pseudopods $(34,37)$. However, this is the first demonstration to our knowledge of the ability of human lymphokine-activated lymphocytes to migrate to and directly attack a fungal target. By immunoperoxidase staining, cells expressing T cell (CD5) and NK (CD56) markers both partially surrounded $C$. neoformans.

The in vivo significance of our findings remains to be determined. C. neoformans is not an obligate intracellular parasite, and extracellular organisms in areas of lymphocytic infiltration are common microscopic features of lesions from patients with

Figure 6. Immunoperoxidase staining of conjugates comprised of lymphocytes and $C$. neoformans. PBMC were depleted of monocytes and B cells by adherence to plastic and nylon wool and then cultured $7 \mathrm{~d}$ with $1,000 \mathrm{U} / \mathrm{ml}$ IL-2. Effectors were incubated with $C$. neoformans for 2 $\mathrm{h}$ and fixed and stained as described in Methods. (Top) Two cells, both of which stain positive for the T cell marker CD5, can be seen partially surrounding budding C. neoformans (arrows). (Bottom) Three cells, all of which stain positive for the NK cell marker CD56, can be seen partially surrounding $C$. neoformans (arrows). 
cryptococcosis who are able to mount an immune response (38). However, the infiltrating lymphocytes have not been characterized. The high effector/fungus ratio required for fungistasis in our experiments does not negate the potential relevance of our findings, since recruited lymphocytes functioning in a physiological environment in vivo may have considerably more antifungal activity than lymphocytes studied in vitro. Finally, although our experiments examined growth inhibition, lymphocytes directly attacking $C$. neoformans may also participate in host defenses by releasing lymphokines that recruit and activate other cell types (e.g., macrophages) capable of anticryptococcal activity.

\section{Acknowledgments}

We thank Drs. Richard Maziarz and Douglas Golenbock for helpful discussions and Cetus Corporation for the gift of IL-2.

This work was supported in part by grants AI-25780 and AI-28408 from the National Institutes of Health.

\section{References}

1. Perfect, J. R. 1989. Cryptococcosis. Infect. Dis. Clin. North Am. 3:77-102.

2. Levitz, S. M. 1991. The ecology of Cryptococcus neoformans and the epidemiology of cryptococcosis. Rev. Infect. Dis. 13:1163-1169.

3. Hill, J. O., and A. G. Harmsen. 1991. Intrapulmonary growth and dissemination of an avirulent strain of Cryptococcus neoformans in mice depleted of $\mathrm{CD}^{+}$or $\mathrm{CD}^{+} \mathrm{T}$ cells. J. Exp. Med. 173:755-758.

4. Huffnagle, G. B., J. L. Yates, and M. F. Lipscomb. 1991. Immunity to a pulmonary Cryptococcus neoformans infection requires both $\mathrm{CD} 4^{+}$and $\mathrm{CD} 8{ }^{+} \mathrm{T}$ cells. J. Exp. Med. 173:793-800.

5. Mody, C. H., M. F. Lipscomb, N. E. Street, and G. B. Toews. 1990. Depletion of $\mathrm{CD4}^{+}\left(\mathrm{L}^{3} 4^{+}\right)$lymphocytes in vivo impairs murine host defense to Cryptococcus neoformans. J. Immunol. 144:1472-1477.

6. Murphy, J. W., and D. O. McDaniel. 1982. In vitro reactivity of natural killer (NK) cells against Cryptococcus neoformans. J. Immunol. 128:1577-1583.

7. Hidore, M. R., N. Nabavi, F. Sonleitner, and J. W. Murphy. 1991. Murine natural killer cells are fungicidal to Cryptococcus neoformans. Infect. Immun 59:1747-1754.

8. Lipscomb, M. F., T. Alvarellos, G. B. Toews, R. Tompkins, Z. Evans, G. Koo, and V. Kumar. 1987. Role of natural killer cells in resistance to Cryptococcus neoformans infections in mice. Am. J. Pathol. 128:354-361.

9. Hidore, M. R., and J. W. Murphy. 1986. Correlation of natural killer cell activity and clearance of Cryptococcus neoformans from mice after adoptive transfer of splenic nylon wool-nonadherent cells. Infect. Immun. 51:547-555.

10. Levitz, S. M., and D. J. DiBenedetto. 1988. Differential stimulation of murine resident peritoneal cells by selectively opsonized encapsulated and acapsular Cryptococcus neoformans. Infect. Immun. 56:2544-2551.

11. Flesch, I. E. A., G. Schwamberger, and S. H. E. Kaufmann. 1989. Fungicidal activity of IFN- $\gamma$-activated macrophages: extracellular killing of $C r y p t o c o c c u s$ neoformans. J. Immunol. 142:3219-3224.

12. Perfect, J. R., D. L. Granger, and D. T. Durack. 1987. Effects of antifungal agents and $y$ interferon on macrophage cytotoxicity for fungi and tumor cells. $J$. Infect. Dis. 156:316-323.

13. Levitz, S. M., and T. P. Farrell. 1990. Growth inhibition of Cryptococcus neoformans by cultured human monocytes: role of the capsule, opsonins, the culture surface, and cytokines. Infect. Immun. 58:1201-1209.

14. Diamond, R. D. 1974. Antibody-dependent killing of Cryptococcus neoformans by human peripheral blood mononuclear cells. Nature (Lond.) 247:148-150.

15. Diamond, R. D., and A. C. Allison. 1976. Nature of the effector cells responsible for antibody-dependent cell-mediated killing of Cryptococcus neoformans. Infect. Immun. 14:716-720.
16. Miller, M. F., T. G. Mitchell, W. J. Storkus, and J. R. Dawson. 1990. Human natural killer cells do not inhibit growth of Cryptococcus neoformans in the absence of antibody. Infect. Immun. 58:639-645.

17. Levitz, S. M., T. P. Farrell, and R. T. Maziarz. 1991. Killing of Cryptococcus neoformans by human peripheral blood mononuclear cells stimulated in culture. J. Infect. Dis. 163:1108-1113.

18. Levitz, S. M. 1991. Activation of human peripheral blood mononuclear cells by interleukin-2 and granulocyte-macrophage colony-stimulating factor to inhibit Cryptococcus neoformans. Infect. Immun. 59:3393-3397.

19. Levitz, S. M., and Tabuni, A. 1991. Binding of Cryptococcus neoformans by human cultured macrophages. Requirements for multiple complement receptors and actin. J. Clin. Invest. 87:528-535.

20. Julius, M. H., E. Simpson, and L. A. Herzenberg. 1973. A rapid method for the isolation of functional thymus-derived murine lymphocytes. Eur. J. Immunol. 3:645-649.

21. Ownby, D. R., and J. McCullough. 1983. An improved technique for separating rosetted from non-rosetted lymphocytes. J. Immunol. Methods. $56: 281-284$.

22. Wysocki, L. J., and V. L. Sato. 1978. "Panning" for lymphocytes: a method for cell selection. Proc. Natl. Acad. Sci. USA. 75:2844-2848.

23. Maziarz, R. T., R. J. Arceci, S. C. Bernstein, L. Frazier, B. R. Smith, M. Kasai, R. Tantravahi, and J. L. Strominger. 1992. A $\gamma \delta^{+}$T-cell leukemia bearing a novel $\mathrm{t}(8 ; 14)(\mathrm{q} 24 \mathrm{C} 1)$ translocation demonstrates spontaneous in vitro natural killer-like activity. Blood. 79:1523-1531.

24. Edwards, J. E., Jr., D. Rotrosen, J. W. Fontaine, C. C. Haudenschild, and R. D. Diamond. 1987. Neutrophil-mediated protection of cultured human vascular endothelial cells from damage by growing Candida albicans hyphae. Blood. 69:1450-1457.

25. Whiteside, T. L., and R. B. Herberman. 1990. Characteristics of natural killer cells and lymphokine-activated killer cells: their role in the biology and treatment of human cancer. Immunol. Allergy Clin. North Am. 10:663-704.

26. Lotzova, E. 1991. Natural killer cells: immunobiology and clinical prospects. Cancer Invest. 9:173-184.

27. Powderly, W. G., G. B. Pier, and R. B. Markham. 1986. T lymphocytemediated protection against Pseudomonas aeruginosa infection in granulocytopenic mice. J. Clin. Invest. 78:375-380.

28. Markham, R. B., J. Goellner, and G. B. Pier. 1984. In vitro T cell-mediated killing of Pseudomonas aeruginosa: I. Evidence that a lymphokine mediates killing. J. Immunol. 133:962-968.

29. Markham, R. B., G. B. Pier, J. J. Goellner, and S. B. Mizel. 1985. In vitro T cell-mediated killing of Pseudomonas aeruginosa: II. The role of macrophages and T cell subsets in T cell killing. J. Immunol. 134:4112-4117.

30. Khan, I. A., K. A. Smith, and L. H. Kasper. 1988. Induction of antigenspecific parasiticidal cytotoxic $\mathrm{T}$ cell splenocytes by a major membrane protein (P30) of Toxoplasma gondii. J. Immunol. 141:3600-3605.

31. Thiele, D. L., and P. E. Lipsky. 1989. The role of cell surface recognition structures in the initiation of MHC-unrestricted "promiscuous" killing by T cells. Immunol. Today. 10:375-381.

32. Phillips, J. H., T. Hori, A. Nagler, N. Bhat, H. Spits, and L. L. Lanier. 1992. Ontogeny of human natural killer (NK) cells. Fetal NK cells mediate

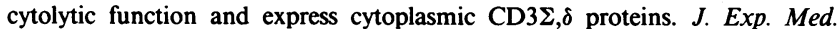
175:1055-1066.

33. Abo, T., S. Sugawara, A. Amenomori, H. Itoh, H. Rikiishi, I. Moro, and K. Kumagai. 1986. Selective phagocytosis of gram-positive bacteria and interleukin 1-like factor production by a subpopulation of large granular lymphocytes. $J$. Immunol. 136:3189-3197.

34. Garcia-Penarrubia, P., F. T. Koster, R. O. Kelley, T. D. McDowęll, and A. D. Bankhurst. 1989. Antibacterial activity of human natural killer cells. $J$. Exp. Med. 169:99-113.

35. Beno, D. W. A., and H. L. Mathews. 1992. Growth inhibition of Candida albicans by interleukin-2-activated splenocytes. Infect. Immun. 60:853-863.

36. Vachino, G., J. A. Gelfand, M. B. Atkins, J. D. Tamerius, P. Demchak, and J. W. Mier. 1991. Complement activation in cancer patients undergoing immunotherapy with interleukin-2 (IL-2): binding of complement and C-reactive protein by IL-2-activated lymphocytes. Blood. 78:2505-2513.

37. Bouwens, L., I. Narayani, and E. Wisse. 1992. High deformability and motility of lymphokine-activated killer cells in vitro and in vivo. J. Leukocyte Biol. 51:214-219.

38. Baker, R. D., and R. K. Haugen. 1955. Tissue changes and tissue diagnosis in cryptococcosis: a study of 26 cases. Am. J. Clin. Pathol. 25:14-24. 